\title{
Comparison of effect of nepafenac and diclofenac ophthalmic solutions on cornea, tear film, and ocular surface after cataract surgery: the results of a randomized trial
}

\author{
This article was published in the following Dove Press journal: \\ Clinical Ophthalmology \\ 4 March 2016 \\ Number of times this article has been viewed
}

\author{
Atsushi Kawahara ${ }^{1-3}$ \\ Tsugiaki Utsunomiya ${ }^{4}$ \\ Yuji Kato² \\ Yoshinori Takayanagi ${ }^{3}$ \\ 'Department of Ophthalmology, \\ Sapporo Tokushukai Hospital, Sapporo, \\ Hokkaido, Japan; ${ }^{2}$ Sapporo Kato Eye \\ Clinic, Sapporo, Hokkaido, Japan; \\ ${ }^{3}$ Takayanagi Clinic, Kushiro, Hokkaido, \\ Japan; ${ }^{4}$ Department of Ophthalmology, \\ Asahikawa Medical University, \\ Asahikawa, Hokkaido, Japan
}

Background: The aim of this study was to compare the effects of nepafenac ophthalmic suspension $0.1 \%$ (Nevanac) and diclofenac sodium ophthalmic solution $0.1 \%$ (Diclod) on the cornea, tear film, and ocular surface after cataract surgery.

Methods: A total of 60 eyes (60 patients) were selected for this study, with no ocular diseases other than cataract (scheduled for cataract surgery by one surgeon). Patients were randomly enrolled to receive nepafenac or diclofenac in the perioperative period, and cataract surgery was performed using torsional microcoaxial phacoemulsification and aspiration with intraocular lens implantation via a transconjunctival single-plane sclerocorneal incision at the 12 o'clock position. We compared intra- and intergroup differences preoperatively and postoperatively in conjunctival and corneal fluorescein staining scores, tear film breakup times, Schirmer's tests, the Dry Eye Related Quality of Life Scores, and tear meniscus areas using anterior segment optical coherence tomography.

Results: The diclofenac group had significantly higher conjunctival and corneal fluorescein staining scores at 4 weeks postoperatively compared with the nepafenac group $(P<0.001)$. Within the diclofenac group, significantly higher conjunctival and corneal fluorescein staining scores were noted at 4 weeks postoperatively than those seen preoperatively $(P<0.001)$ and at 1 week postoperatively $(P<0.001)$. No statistically significant differences were found in any other items.

Conclusions: Nepafenac ophthalmic suspension $0.1 \%$ is considered safe for the corneal epithelium after cataract surgery.

Keywords: nepafenac, diclofenac, cornea, tear film, ocular surface, cataract surgery

\section{Introduction}

Currently, two drug groups are used to control inflammation after cataract surgery: steroids and nonsteroidal anti-inflammatory drugs (NSAIDs). Although ophthalmic steroids reduce postoperative inflammation by inhibiting phospholipase $\mathrm{A}_{2}$ production, their use may increase the risk for intraocular pressure elevation or infection. ${ }^{1}$ NSAIDs exert an equivalent anti-inflammatory effect by inhibiting cyclooxygenases (COXs), but steroid adverse effects can be avoided. Topical NSAIDs have become widely accepted for controlling ocular inflammation and are more recommended than topical steroids for the control of inflammation after cataract surgery. ${ }^{2-4}$

The most common adverse effects of topical NSAIDs are reported to be stinging, irritation, superficial punctate keratitis, corneal infiltrates, and corneal melting; the
Correspondence: Atsushi Kawahara Takayanagi Clinic, I-3-5, Minamiodori, Kushiro, Hokkaido 085-084I, Japan

Tel +8 I I54 43021 I

Fax +8I I54 430210

Email atsusi-k@coral.plala.or.jp 
complications of NSAIDs are considerably less frequent than those of steroids. ${ }^{5}$ By inhibiting COX activity in the arachidonic acid cascade, NSAIDs decrease prostaglandin synthesis. Prostaglandins are essential for protein and DNA synthesis in epidermal cells; therefore, postoperative use of NSAIDs may affect corneal epithelial wound healing. ${ }^{6,7}$ In particular, diclofenac sodium significantly delayed early wound healing in scraped rabbit corneal epithelium and reepithelialization after penetrating keratoplasty. ${ }^{7}$ Nepafenac has a unique prodrug structure compared with other topical NSAID eye drops, allowing a rapid penetration through the cornea to ultimately reach the anterior chamber and posterior segment of the eye..$^{8-10}$ In the aqueous humor, nepafenac is converted to amfenac, a potent NSAID. ${ }^{8}$ It may be possible that corneal damage after cataract surgery would be milder with the use of nepafenac rather than diclofenac sodium.

The main objective of our study was to compare the effects of nepafenac ophthalmic suspension $0.1 \%$ (Nevanac; Alcon, Tokyo, Japan) and diclofenac sodium ophthalmic solution $0.1 \%$ (Diclod; Wakamoto, Tokyo, Japan) on the cornea, tear film, and ocular surface after cataract surgery. To the best of our knowledge, this is the first randomized study comparing the safety of nepafenac and diclofenac sodium eye drops on ocular surface after cataract surgery.

\section{Materials and methods}

\section{Trial registration}

UMIN000017667; May 25, 2015.

\section{Study design}

This was a prospective, randomized, parallel-group study designed to evaluate the effects of nepafenac and diclofenac ophthalmic solutions on the cornea at 4 weeks after cataract surgery in patients. The study consisted of five visits, which included the inspection before surgery and the screening visit, the cataract surgery visit (day 0), and three postoperative follow-up visits (on days 1, 7, and 28). The institutional review board of the Sapporo Tokushukai Hospital approved this study, which adhered to the tenets of the Declaration of Helsinki. All patients provided informed consent after receiving an explanation of the nature and possible consequences of the study.

We included consecutive patients undergoing routine uniocular cataract surgery at the Department of Ophthalmology, Sapporo Tokushukai Hospital. The patients had nuclear senile cataracts grade $2-3$ as per the Emery-Little classification. The preoperative inclusion criteria were as follows: 1) a transparent cornea, 2) no dry eye, blepharitis or associated lid diseases, glaucoma, or retinal disease, and 3) no history of ocular injury or surgery. The postoperative exclusion criteria included perioperative and postoperative complications within the follow-up period. Patients who failed to attend postoperative appointments and who dosed the study medication improperly were also excluded.

Patients were randomly divided into two groups according to the prescribed NSAID (nepafenac or diclofenac ophthalmic solutions) using a computer-generated stratified random allocation. All patients were instructed to stop the use of all ophthalmic solutions for at least 2 weeks prior to surgery, although 32 patients used pirenoxine (Kary Uni; Santen Pharmaceutical, Osaka, Japan) and 9 patients used cyanocobalamin (Sancoba; Santen Pharmaceutical) when they approved participation to the clinical research. Patients received levofloxacin (Cravit; Santen Pharmaceutical) three times daily into their operated eye beginning 3 days preoperatively. On the day of surgery, patients received an NSAID (nepafenac or diclofenac) hourly for three doses in their operated eye beginning 3 hours before surgery. For pupillary dilation, all patients received two drops each of tropicamide (Mydrin-P; Santen Pharmaceutical) and phenylephrine hydrochloride (Neosynesin; Kowa, Nagoya, Japan) into their operated eye every 10 minutes for four doses beginning 1 hour before surgery. Ofloxacin ointment (Tarivid ophthalmic ointment; Santen Pharmaceutical) was instilled beneath a sterile monocular patch at the end of surgery. During surgery, the patients received no topical, systemic, or subconjunctival anti-inflammatory medication. The patients received no other medication for the first 24 hours and returned to the office on the first postoperative day. After the removal of their dressing and the first postoperative examinations, the postoperative therapy was started. The postoperative therapy included a topical combination of levofloxacin, betamethasone (Linolosal; Wakamoto), and an NSAID three times a day for 1 week, followed by an NSAID alone three times a day for an additional 3 weeks.

All surgeries were performed by a single, experienced surgeon $(\mathrm{AK})$ by using the same phaco machine (Infiniti Vision System with OZil Intelligent Phaco Torsional Technology; Alcon). After topical anesthesia with 4\% lidocaine hydrochloride, a $2.4 \mathrm{~mm}$ transconjunctival singleplane sclerocorneal incision ${ }^{11}$ was created at the 12 o'clock position. A corneal side port was not created. In all eyes, an IOL (PY60AD; Hoya, Tokyo, Japan) was implanted in the 
capsular bag after torsional microcoaxial phacoemulsification and residual cortex removal. The incision was self-sealing.

\section{Patient evaluations}

Clinical assessments of the conjunctival and corneal fluorescein staining scores, tear film breakup times (BUT), Schirmer's tests, Dry Eye Related Quality of Life Scores (DEQS), ${ }^{12}$ and tear meniscus areas using anterior segment optical coherence tomography (OCT) were performed preoperatively and at the follow-up appointments at 1 week ( 7 days) and 4 weeks (28 days) after surgery. The conjunctival and corneal fluorescein staining scores were evaluated using the degree of staining, which was graded from 0 to 3 : no staining (0), mild staining (1), moderate staining (2), and severe staining (3). ${ }^{12,13}$ The scores of the cornea and the nasal and temporal conjunctiva staining using a blue-free barrier filter ${ }^{13}$ were combined to obtain a total score for each eye. The BUTs were measured using fluorescein with a metronome; the average of three consecutive BUTs was calculated. The 5-minute Schirmer's tests were performed using sterile strips without administering anesthesia. The conjunctival and corneal fluorescein staining scores, BUTs, and Schirmer's test results were obtained in a dimly lit room. For ocular symptoms, we used the DEQS questionnaire, which had good reliability, validity, specificity, and responsiveness and was a useful instrument for assessing ocular symptoms. ${ }^{12}$ The summary score ranged from 0 to 100 , with a higher score representing greater disability. The patients were instructed to complete the DEQS questionnaire by one investigator (AK). The tear meniscus area was measured by Fourier domain swept-source anterior segment OCT (SS-1000; Tomey, Nagoya, Japan). Stable ambient room light was maintained during the OCT examinations. The original OCT images were magnified by $300 \%$. Outlines of both the upper and lower tear menisci at the central cornea, which consisted of the corneal surface, lid margin, and tear meniscus surface, were plotted manually using the software calipers. The area within the plotted lines, the tear meniscus area, was calculated automatically by the program. Tear meniscus area is a noninvasive and practical method for quantitatively evaluating tear fluid, with satisfactory intergrader and interimage repeatability. ${ }^{14}$ The parameters were evaluated in the following order: DEQS, tear meniscus area, BUT, conjunctival and corneal fluorescein staining scores, and Schirmer's test. In addition, we compared the group differences preoperatively and postoperatively for the amount of inflammation using the laser flare meter (FM-600;
Kowa) preoperatively and at the follow-up appointments 1 day, 1 week, and 4 weeks after surgery.

\section{Statistical analysis}

Intergroup comparisons were performed using the MannWhitney $U$-test (patient characteristics and flare scores) after normality and $F$ tests. Inter- and intragroup comparisons were performed using the Friedman test (conjunctival and corneal fluorescein staining scores, BUT, Schirmer's test, DEQS scores, and tear meniscus area) after normality and Levene's tests. Scheffe's test was used for multiple comparisons. The sex distribution and the right and left distribution of the eyes were evaluated using Fisher's exact test. Ekuseru-Toukei 2010 (Social Survey Research Information, Tokyo, Japan) was used to perform the statistical analyses. $P<0.05$ was considered statistically significant.

\section{Results}

Of the 63 study patients initially enrolled, 3 were excluded because of improper dosing of study medication $(n=1)$ or loss to follow-up at the last postoperative visit, which took place 4 weeks after surgery $(n=2)$. The mean age of the 60 patients (18 men and 42 women) included for analysis was 71.8 \pm 8.1 (range, 58-85) years. The mean best-corrected visual acuity 4 weeks after operation was $-0.05 \pm 0.07$ (range, -0.08 to 0.15 ) logarithm of the minimum angle of resolution. Nineteen patients had hypertension and received medication for it, but all patients were free of any other systemic diseases.

Table 1 summarizes the patient characteristics in both groups. Each group consisted of 30 patients (30 eyes). The results of the flare scores preoperatively and at 1 day, 1 week, and 4 weeks after surgery are shown in Table 2 . Because the

Table I Patient characteristics

\begin{tabular}{llll}
\hline Parameter & $\begin{array}{l}\text { Nepafenac } \\
\text { group }\end{array}$ & $\begin{array}{l}\text { Diclofenac } \\
\text { group }\end{array}$ & $P$-value \\
\hline Age (years) & $71.1 \pm 9.4$ & $72.5 \pm 6.4$ & 0.72 \\
BCVA 4 weeks after & $-0.03 \pm 0.09$ & $-0.07 \pm 0.04$ & 0.14 \\
$\begin{array}{l}\text { operation (log MAR) } \\
\text { Operating time (seconds) }\end{array}$ & $386 \pm 132$ & $363 \pm 125$ & 0.67 \\
$\begin{array}{l}\text { Sex, n (\%) } \\
\quad \text { Male }\end{array}$ & $6(20)$ & $12(40)$ & 0.16 \\
$\quad$ Female & $24(80)$ & $18(60)$ & \\
$\begin{array}{l}\text { Study eye, n (\%) } \\
\quad \text { Right } \\
\quad \text { Left }\end{array}$ & $16(53)$ & $18(60)$ & 0.79 \\
\hline
\end{tabular}

Note: Values are represented as mean \pm standard deviation unless otherwise specified. Abbreviations: BCVA, best-corrected visual acuity; log MAR, logarithm of the minimum angle of resolution. 
Table 2 Flare scores (photon $\mathrm{c} / \mathrm{ms}$ )

\begin{tabular}{llll}
\hline Exam & $\begin{array}{l}\text { Nepafenac } \\
\text { group }\end{array}$ & $\begin{array}{l}\text { Diclofenac } \\
\text { group }\end{array}$ & $P$-value \\
\hline $\begin{array}{l}\text { Before operation } \\
\text { After operation }\end{array}$ & $8.0 \pm 0.9$ & $8.0 \pm 0.7$ & 0.84 \\
I day & $29.2 \pm 5.2$ & $27.6 \pm 4.9$ & 0.74 \\
I week & $15.1 \pm 1.0$ & $13.8 \pm 0.6$ & 0.41 \\
4 weeks & $9.1 \pm 0.8$ & $8.0 \pm 0.5$ & 0.61 \\
\hline
\end{tabular}

Note: Values are represented as mean \pm standard error unless otherwise specified.

differences between the factors in Tables 1 and 2 were not statistically significant, it can be concluded that the functional results were similar with both ophthalmic solutions regarding the anti-inflammatory effects.

Tables 3-8 show the results of the clinical assessments. Tables 3 and 4 show the conjunctival and corneal fluorescein staining scores. The diclofenac group had significantly higher mean conjunctival and corneal fluorescein staining scores at 4 weeks postoperatively compared with the nepafenac group $(P<0.001)$. Within the diclofenac group, significantly higher mean conjunctival and corneal fluorescein staining scores were noted at 4 weeks postoperatively than that preoperatively $(P<0.001)$ or at 1 week postoperatively $(P<0.001)$. Of those patients in the diclofenac group, $26(87 \%)$ had an increase in only the corneal scores from 1 to 4 weeks postoperatively. Table 5 shows the mean BUTs, Table 6 shows the mean Schirmer's tests, Table 7 shows the mean DEQS scores, and Table 8 shows the tear meniscus areas. No significant intra- or intergroup differences were found in any of the values given in Tables 5-8.

\section{Discussion}

Ocular surface disorders after cataract surgery can result in visual deterioration and patient discomfort, which may be further aggravated by the toxicity of eye drops. ${ }^{15}$ Topical NSAIDs are especially known to be associated with ocular surface disturbances. The common commercially available NSAIDs eye drops in Japan that are used for inflammation at an early stage after cataract surgery are diclofenac, bromfenac, and nepafenac. Diclofenac is highly cytotoxic to corneal epithelium. ${ }^{16,17}$ When comparing different NSAIDs, Ayaki et al ${ }^{18}$ reported that the survival of human corneal and conjunctival epithelial cells in in vitro models was similar between diclofenac and bromfenac; Sawazaki et a ${ }^{19}$ reported that diclofenac suppressed corneal surface damage but that bromfenac did not reduce the damage in a rat model of dry eye; and Acosta et $\mathrm{a}^{20}$ reported that in contrast to diclofenac, nepafenac did not exhibit local anesthetic effects in a cat model, which resulted in impaired corneal epithelial wound healing. Our study results indicated that diclofenac ophthalmic solution showed a significant effect on keratoconjunctival epithelial damage. The cytotoxicity of diclofenac was represented by the retardation of corneal epithelial healing, ${ }^{21}$ decrease in cell growth, ${ }^{22}$ and higher incidence of persistent epithelial defects. ${ }^{23}$ The mechanism associated with diclofenac not only blocks the COX pathway but also diminishes the pool of available arachidonic acid. Arachidonic acid is an important component of cellular structural integrity; the lack of its availability and the potentially increased permeability of cellular membranes may lead to corneal epithelial cell death and keratolysis. ${ }^{24,25}$ According to the mean conjunctival and corneal fluorescein staining score in this study, the diclofenac group had significantly higher mean scores at 4 weeks postoperatively than the nepafenac group, and significantly higher mean scores were noted at 4 weeks postoperatively than preoperatively and at 1 week postoperatively within the diclofenac group. Twenty-six patients (87\%) in the diclofenac group had an increase in only the corneal scores from 1 to 4 weeks postoperatively. Meanwhile, the cytotoxicity of preservatives to corneal epithelium has been investigated. ${ }^{26-28}$ Ophthalmic solutions contain preservatives to maintain the shelf life of the product and to prevent contamination during the treatment period of the patient. As a preservative, nepafenac eye drops contain benzalkonium chloride; diclofenac sodium eye drops contain chlorobutanol. It is necessary to further investigate the origin of toxicity and damage to the corneal epithelium, because the present study had limited product information about preservatives and possible interactions between active ingredients and preservatives.

Table 3 Conjunctival and corneal fluorescein staining scores

\begin{tabular}{|c|c|c|c|c|c|c|}
\hline Group & $\begin{array}{l}\text { Before } \\
\text { operation }\end{array}$ & $\begin{array}{l}\text { I week after } \\
\text { operation }\end{array}$ & $\begin{array}{l}4 \text { weeks after } \\
\text { operation }\end{array}$ & $P$-value ${ }^{a}$ & $P$-value ${ }^{b}$ & $P$-value \\
\hline Nepafenac & $0.6 \pm 0.1$ & $1.1 \pm 0.1$ & $1.0 \pm 0.2$ & 0.69 & 0.98 & 0.98 \\
\hline Diclofenac & $0.6 \pm 0.2$ & $1.1 \pm 0.2$ & $2.3 \pm 0.3$ & 0.34 & $<0.00 I^{*}$ & $<0.00 I^{*}$ \\
\hline$P$-value ${ }^{d}$ & 0.81 & 0.98 & $<0.00 I^{*}$ & & & \\
\hline
\end{tabular}

Notes: Values are represented as mean \pm standard error unless otherwise specified. a Scheffe's comparison $P$-values between before operation and I week after operation. 'Scheffe's comparison P-values between before operation and 4 weeks after operation. 'Scheffe's comparison $P$-values between I week after operation and 4 weeks after operation. ¿Scheffe's comparison $P$-values between nepafenac and diclofenac groups at each time point. *Significant value $P<0.05$. 
Table 4 Conjunctival and corneal fluorescein staining scores collection

\begin{tabular}{|c|c|c|c|c|c|c|}
\hline \multirow{2}{*}{$\begin{array}{l}\text { Fluorescein } \\
\text { scores }\end{array}$} & \multicolumn{3}{|l|}{ Nepafenac group } & \multicolumn{3}{|l|}{ Diclofenac group } \\
\hline & $\begin{array}{l}\text { Before operation } \\
(n=30)\end{array}$ & $\begin{array}{l}\text { I week after } \\
\text { operation }(n=30)\end{array}$ & $\begin{array}{l}4 \text { weeks after } \\
\text { operation }(n=30)\end{array}$ & $\begin{array}{l}\text { Before } \\
\text { operation }(n=30)\end{array}$ & $\begin{array}{l}\text { I week after } \\
\text { operation }(n=30)\end{array}$ & $\begin{array}{l}4 \text { weeks after } \\
\text { operation }(n=30)\end{array}$ \\
\hline 0 & 12 & 4 & 8 & 22 & 12 & 0 \\
\hline I & 18 & 22 & 18 & 2 & 10 & 12 \\
\hline 2 & 0 & 0 & 0 & 4 & 4 & 6 \\
\hline 3 & 0 & 4 & 4 & 0 & 2 & 8 \\
\hline 4 & 0 & 0 & 0 & 2 & 0 & 2 \\
\hline 5 & 0 & 0 & 0 & 0 & 2 & 0 \\
\hline 6 & 0 & 0 & 0 & 0 & 0 & 2 \\
\hline $7-9$ & 0 & 0 & 0 & 0 & 0 & 0 \\
\hline Average (mean) & $0.6 \pm 0.1$ & $1.1 \pm 0.1$ & $1.0 \pm 0.2$ & $0.6 \pm 0.2$ & $1.1 \pm 0.2$ & $2.3 \pm 0.3$ \\
\hline
\end{tabular}

Note: Average values are represented as mean \pm standard error.

Table 5 Tear film breakup time (seconds)

\begin{tabular}{|c|c|c|c|c|c|c|}
\hline Group & $\begin{array}{l}\text { Before } \\
\text { operation }\end{array}$ & $\begin{array}{l}\text { I week after } \\
\text { operation }\end{array}$ & $\begin{array}{l}4 \text { weeks after } \\
\text { operation }\end{array}$ & $P$-value ${ }^{a}$ & $P$-value ${ }^{b}$ & $P$-value \\
\hline Nepafenac & $7.9 \pm 0.5$ & $8.1 \pm 0.5$ & $8.2 \pm 0.4$ & 0.99 & 0.99 & 0.99 \\
\hline Diclofenac & $8.5 \pm 0.6$ & $8.2 \pm 0.5$ & $8.3 \pm 0.5$ & 0.99 & 0.97 & 0.99 \\
\hline$P$-value ${ }^{d}$ & 0.82 & 0.75 & 0.59 & & & \\
\hline
\end{tabular}

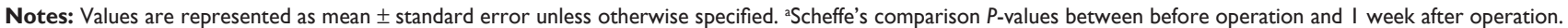
'Scheffe's comparison $P$-values between before operation and 4 weeks after operation. 'Scheffe's comparison $P$-values between I week after operation and 4 weeks after operation. 'Scheffe's comparison P-values between nepafenac and diclofenac groups at each time point.

Table 6 Schirmer's test $(\mathrm{mm})$

\begin{tabular}{|c|c|c|c|c|c|c|}
\hline Group & $\begin{array}{l}\text { Before } \\
\text { operation }\end{array}$ & $\begin{array}{l}\text { I week after } \\
\text { operation }\end{array}$ & $\begin{array}{l}4 \text { weeks after } \\
\text { operation }\end{array}$ & $P$-value ${ }^{a}$ & $P$-value ${ }^{b}$ & $P$-value \\
\hline Nepafenac & $16.9 \pm 1.8$ & $|8.| \pm \mid .4$ & $18.5 \pm 1.6$ & 0.54 & 0.67 & 0.99 \\
\hline Diclofenac & $16.2 \pm 1.5$ & $16.0 \pm 1.6$ & $15.5 \pm 1.4$ & 0.99 & 0.99 & 0.99 \\
\hline$P$-value ${ }^{d}$ & 0.99 & 0.78 & 0.67 & & & \\
\hline
\end{tabular}

Notes: Values are represented as mean \pm standard error unless otherwise specified. a'Scheffe's comparison $P$-values between before operation and I week after operation. 'Scheffe's comparison $P$-values between before operation and 4 weeks after operation. 'Scheffe's comparison $P$-values between I week after operation and 4 weeks after operation. 'Scheffe's comparison $P$-values between nepafenac and diclofenac groups at each time point.

Table 7 Dry Eye Related Quality of Life Scores

\begin{tabular}{lllllrr}
\hline Group & $\begin{array}{l}\text { Before } \\
\text { operation }\end{array}$ & $\begin{array}{l}\text { I week after } \\
\text { operation }\end{array}$ & $\begin{array}{l}\text { 4 weeks after } \\
\text { operation }\end{array}$ & P-value & $\boldsymbol{P}_{\text {-value }}^{\mathrm{b}}$ & $\boldsymbol{P}_{\text {-value }}^{\mathrm{c}}$ \\
\hline Nepafenac & $8.8 \pm 2.0$ & $7.0 \pm 1.5$ & $6.2 \pm 1.6$ & 0.54 & 0.67 & 0.99 \\
Diclofenac $^{\text {P-value }}{ }^{\mathrm{d}}$ & $7.1 \pm 1.0$ & $7.5 \pm 1.6$ & $8.1 \pm 1.7$ & 0.99 & 0.99 & 0.99 \\
\hline
\end{tabular}

Notes: Values are represented as mean \pm standard error unless otherwise specified. a'Scheffe's comparison P-values between before operation and I week after operation. 'Scheffe's comparison P-values between before operation and 4 weeks after operation. 'Scheffe's comparison $P$-values between I week after operation and 4 weeks after operation. 'Scheffe's comparison $P$-values between nepafenac and diclofenac groups at each time point.

Table 8 Tear meniscus area $\left(\mathrm{mm}^{2}\right)$

\begin{tabular}{|c|c|c|c|c|c|c|}
\hline Group & $\begin{array}{l}\text { Before } \\
\text { operation }\end{array}$ & $\begin{array}{l}\text { I week after } \\
\text { operation }\end{array}$ & $\begin{array}{l}4 \text { weeks after } \\
\text { operation }\end{array}$ & $P$-value ${ }^{a}$ & $P$-value ${ }^{b}$ & $P$-value ${ }^{c}$ \\
\hline Nepafenac & $0.04 I \pm 0.002$ & $0.046 \pm 0.004$ & $0.04 I \pm 0.003$ & 0.88 & 0.99 & 0.88 \\
\hline Diclofenac & $0.039 \pm 0.004$ & $0.039 \pm 0.003$ & $0.037 \pm 0.003$ & 0.99 & 0.99 & 0.99 \\
\hline$P$-value ${ }^{d}$ & 0.99 & 0.99 & 0.99 & & & \\
\hline
\end{tabular}

Notes: Values are represented as mean \pm standard error unless otherwise specified. a Scheffe's comparison P-values between before operation and I week after operation. 'Scheffe's comparison $P$-values between before operation and 4 weeks after operation. 'Scheffe's comparison $P$-values between I week after operation and 4 weeks after operation. 'Scheffe's comparison $P$-values between nepafenac and diclofenac groups at each time point. 
In this study, no significant differences were found in any items between and within the diclofenac group for the BUT, Schirmer's test, and tear meniscus area results. This finding suggested that the damage to the corneal epithelium accounted for most of the adverse effects of diclofenac on the ocular surface and that nepafenac had little influence on the cornea, tear film, and ocular surface. However, the small sample size may not be able to reach significance in this study. In the BUT, diclofenac group seemed to have better scores than nepafenac group. In the Schirmer's test, nepafenac group had consistently better scores than diclofenac group following 1 and 4 weeks of surgery. No statistically significant differences between both NSAIDs were found in the DEQS scores as well, although there were significant differences in the conjunctival and corneal fluorescein staining scores. This observation might have resulted from the fact that only one eye of each patient was evaluated in this study; this was done to prevent the failure of attending postoperative appointments and the improper dosing of study medication. Future studies with an increased number of patients and involving binocular surgery patients must be undertaken to assess them. Taken together, the daily diclofenac dosing 4 weeks postoperatively showed significant toxicity and damage to the corneal epithelium when compared with nepafenac.

Three previous studies have reported the causes of dry eye symptoms after successful cataract surgery. Li et al ${ }^{15}$ reported that the misuse of eye drops was one of the major pathogenic factors that caused dry eye after cataract surgery. Cho and $\mathrm{Kim}^{29}$ reported that intraoperative exposure to microscope light aggravated dry eye symptoms and signs after cataract surgery. Oh et $\mathrm{al}^{30}$ reported that ocular surface damage after cataract surgery was correlated with operating time. The exposure time to microscope light and operating time are believed to correlate with each other. In our study, improper dosing was excluded and a significant difference was not found in the operating time between both groups.

In conclusion, we found that there was a significant difference in the damage to corneal epithelium between nepafenac and diclofenac, and that nepafenac ophthalmic suspension $0.1 \%$ can be considered safe for corneal epithelium after cataract surgery.

\section{Disclosure}

The authors report no conflicts of interest in this work.

\section{References}

1. McGhee CN, Dean S, Danesh-Meyer H. Locally administered ocular corticosteroids: benefits and risks. Drug Saf. 2002;25(1):33-55.
2. Kessel L, Tendal B, Jørgensen KJ, et al. Post-cataract prevention of inflammation and macular edema by steroid and nonsteroidal anti-inflammatory eye drops. A systematic review. Ophthalmology. 2014;121(10): 1915-1924.

3. Qu M, Wang Y, Yang L, Zhou Q. Different cellular effects of four antiinflammatory eye drops on human corneal epithelial cells: independent in active components. Mol Vis. 2011;17:3147-3155.

4. Assouline M, Renard G, Arne JL, et al. A prospective randomized trial of topical soluble $0.1 \%$ indomethacin versus $0.1 \%$ diclofenac versus placebo for the control of pain following excimer laser photorefractive keratectomy. Ophthalmic Surg Lasers. 1998;29(5):365-374.

5. Guidera AC, Luchs JI, Udell IJ. Keratitis, ulceration, and perforation associated with topical nonsteroidal anti-inflammatory drugs. Ophthalmology. 2001;108(5):936-944.

6. Lindstrom R. The pharmacologic and pathophysiologic rationale for using NSAIDs in ocular inflammatory disease and ocular surgery. Int Ophthalmol Clin. 2006;46(4):7-11.

7. Hersh PS, Rice BA, Baer JC, et al. Topical nonsteroidal agents and corneal wound healing. Arch Ophthalmol. 1990;108(4):577-583.

8. Walters T, Raizman M, Ernest P, Gayton J, Lehmann R. In vivo pharmacokinetics and in vitro pharmacodynamics of nepafenac, amfenac, ketorolac, and bromfenac. J Cataract Refract Surg. 2007;33(9): 1539-1545.

9. Kapin MA, Yanni JM, Brady MT, et al. Inflammation-mediated retinal edema in the rabbit is inhibited by topical nepafenac. Inflammation. 2003;27(5):281-291.

10. Gamache DA, Graff G, Brady MT, Spellman JM, Yanni JM. Nepafenac, a unique nonsteroidal prodrug with potential utility in the treatment of trauma-induced ocular inflammation: I. Assessment of anti-inflammatory efficacy. Inflammation. 2000;24(4):357-370.

11. Sugai S, Yoshitomi F, Oshika T. Transconjunctival single-plane sclerocorneal incisions versus clear corneal incisions in cataract surgery. J Cataract Refract Surg. 2010;36(9):1503-1507.

12. Sakane Y, Yamaguchi M, Yokoi N, et al. Development and validation of the Dry Eye-Related Quality-of-Life Score questionnaire. JAMA Ophthalmol. 2013;131(10):1331-1338.

13. Koh S, Watanabe H, Hosohata J, et al. Diagnosing dry eye using a blue-free barrier filter. Am J Ophthalmol. 2003;136(3):513-519.

14. Fukuda R, Usui T, Miyai T, Yamagami S, Amano S. Tear meniscus evaluation by anterior segment swept-source optical coherence tomography. Am J Ophthalmol. 2013;155(4):620-624, 624.e1-e2.

15. Li XM, Hu L, Hu J, Wang W. Investigation of dry eye disease and analysis of the pathogenic factors in patients after cataract surgery. Cornea. 2007;26(9 Suppl 1):S16-S20.

16. Hsu JK, Johnston WT, Read RW, et al. Histopathology of corneal melting associated with diclofenac use after refractive surgery. $J$ Cataract Refract Surg. 2003;29(2):250-256.

17. O'Brien TP, Li QJ, Sauerburger F, Reviglio VE, Rana T, Ashraf MF. The role of matrix metalloproteinases in ulcerative keratolysis associated with perioperative diclofenac use. Ophthalmology. 2001;108(4): 656-659.

18. Ayaki M, Yaguchi S, Iwasawa A, Koide R. Cytotoxicity of ophthalmic solutions with and without preservatives to human corneal endothelial cells, epithelial cells and conjunctival epithelial cells. Clin Experiment Ophthalmol. 2008;36(6):553-559.

19. Sawazaki R, Ishihara T, Usui S, et al. Diclofenac protects cultured human corneal epithelial cells against hyperosmolarity and ameliorates corneal surface damage in a rat model of dry eye. Invest Ophthalmol Vis Sci. 2014;55(4):2547-2556.

20. Acosta MC, Luna C, Graff G, et al. Comparative effects of the nonsteroidal anti-inflammatory drug nepafenac on corneal sensory nerve fibers responding to chemical irritation. Invest Ophthalmol Vis Sci. 2007;48(1): $182-188$.

21. Tomas-Barberan S, Fagerholm P. Influence of topical treatment on epithelial wound healing and pain in the early postoperative period following photorefractive keratectomy. Acta Ophthalmol Scand. 1999;77(2): 135-138. 
22. Takahashi N, Miyakoshi M, Taka N, Kurihara T, Fujikawa K. [Cytotoxic effects of diclofenac sodium]. Nihon Ganka Gakkai Zasshi. 1993;97(2): 145-149. Japanese.

23. Shimazaki J, Saito H, Yang HY, Toda I, Fujishima H, Tsubota K. Persistent epithelial defect following penetrating keratoplasty: an adverse effect of diclofenac eyedrops. Cornea. 1995;14(6):623-627.

24. Uyemura SA, Santos AC, Mingatto FE, Jordani MC, Curti C. Diclofenac sodium and mefenamic acid: potent inducers of the membrane permeability transition in renal cortex mitochondria. Arch Biochem Biophys. 1997;342(2):231-235.

25. Ku EC, Lee W, Kothari HV, Scholer DW. Effect of diclofenac sodium on the arachidonic acid cascade. Am J Med. 1986;80(4B):18-23.
26. Baudouin C. Allergic reaction to topical eyedrops. Curr Opin Allergy Clin Immunol. 2005;5(5):459-463.

27. Tripathi BJ, Tripathi RC. Cytotoxic effects of benzalkonium chloride and chlorobutanol on human corneal epithelial cells in vitro. Lens Eye Toxic Res. 1989;6(3):395-403.

28. Burstein NL. Preservative cytotoxic threshold for benzalkonium chloride and chlorhexidine digluconate in cat and rabbit corneas. Invest Ophthalmol Vis Sci. 1980;19(3):308-313.

29. Cho YK, Kim MS. Dry eye after cataract surgery and associated intraoperative risk factors. Korean J Ophthalmol. 2009;23(2):65-73.

30. Oh T, Jung Y, Chang D, Kim J, Kim H. Changes in the tear film and ocular surface after cataract surgery. Jpn J Ophthalmol. 2012;56(2):113-118.
Clinical Ophthalmology

\section{Publish your work in this journal}

Clinical Ophthalmology is an international, peer-reviewed journal covering all subspecialties within ophthalmology. Key topics include: Optometry; Visual science; Pharmacology and drug therapy in eye diseases; Basic Sciences; Primary and Secondary eye care; Patien Safety and Quality of Care Improvements. This journal is indexed on

Submit your manuscript here: http://www.dovepress.com/clinical-ophthalmology-journal

\section{Dovepress}

PubMed Central and CAS, and is the official journal of The Society of Clinical Ophthalmology (SCO). The manuscript management system is completely online and includes a very quick and fair peer-review system, which is all easy to use. Visit http://www.dovepress.com/ testimonials.php to read real quotes from published authors. 